\title{
Contribution to the Study of the Relation between Microstructure and Electrochemical Behavior of Iron-Based FeCoC Ternary Alloys
}

\author{
Farida Benhalla-Haddad, ${ }^{1}$ Sif Eddine Amara, ${ }^{1}$ Abdelkader Benchettara, ${ }^{1}$ \\ Kamel Taibi, ${ }^{2}$ and Rafika Kesri ${ }^{1}$ \\ ${ }^{1}$ Laboratory of Electrochemistry, Corrosion, Metallurgy and Inorganic Chemistry, Faculty of Chemistry, \\ University of Science and Technology Houari Boumediene, P.O. Box 32, El-Alia, Bab Ezzouar, Algiers 16111, Algeria \\ ${ }^{2}$ Laboratory of Materials Science and Engineering, University of Science and Technology Houari Boumediene, P.O. Box 32, El-Alia, \\ Bab Ezzouar, Algiers 16111, Algeria
}

Correspondence should be addressed to Farida Benhalla-Haddad, haddad.farida@gmail.com

Received 21 November 2011; Accepted 6 December 2011

Academic Editor: Christophe A. Marquette

Copyright (C) 2012 Farida Benhalla-Haddad et al. This is an open access article distributed under the Creative Commons Attribution License, which permits unrestricted use, distribution, and reproduction in any medium, provided the original work is properly cited.

This work deals with the relation between microstructure and electrochemical behavior of four iron-based FeCoC ternary alloys. First, the arc-melted studied alloys were characterized using differential thermal analyses and scanning electron microscopy. The established solidification sequences of these alloys show the presence of two primary crystallization phases $(\delta(\mathrm{Fe})$ and graphite) as well as two univariante lines : peritectic $\mathrm{L}+\delta(\mathrm{Fe}) \leftrightarrow \gamma(\mathrm{Fe})$ and eutectic $\mathrm{L} \leftrightarrow \gamma(\mathrm{Fe})+\mathrm{C}_{\text {graphite. }}$ The ternary alloys were thereafter studied in nondeaerated solution of $10^{-3} \mathrm{M} \mathrm{NaHCO} 3+10^{-3} \mathrm{M} \mathrm{Na}_{2} \mathrm{SO}_{4}$, at $25^{\circ} \mathrm{C}$, by means of the potentiodynamic technique. The results indicate that the corrosion resistance of the $\mathrm{FeCoC}$ alloys depends on the carbon amount and the morphology of the phases present in the studied alloys.

\section{Introduction}

Cobalt is one of the first transition series of elements. It lays between $\mathrm{Fe}$ and $\mathrm{Ni}$ and close to $\mathrm{Cu}$ in the periodic table. In nature, it shows a strong spatial association with these metals. Cobalt is a critical metal and it has many strategic and irreplaceable industrial uses (supperalloys, magnets, corrosionand wear-resistant alloys, high-speed steels, cemented carbides, diamond tool, etc.) [2-4]. Since cobalt shows great application potential, it has been widely studied.

This work is an academic study. It deals with the relation between the microstructure and electrochemical behavior of four iron-based $\mathrm{FeCoC}$ ternary alloys.

The solidification behavior of these alloys was studied in an earlier work [1]. This latter leads to the liquidus surface projection plot. In this paper, we undertake a study on electrochemical behavior of these alloys in nondeaerated solution of $10^{-3} \mathrm{M} \mathrm{NaHCO}_{3}+10^{-3} \mathrm{M} \mathrm{Na}_{2} \mathrm{SO}_{4}$, at $25^{\circ} \mathrm{C}$.

\section{Experiment}

The studied alloys were arc melted in an argon gas atmosphere from pure elements (iron at $99.98 \mathrm{pct}$ and cobalt at 99.5 pct from Aldrich Chemical Co.) and graphite. The solidliquid and the solid-solid transformation temperatures were followed by a DTA-Netzsch 404S differential thermal analysis (cooling rate of $10 \mathrm{~K} / \mathrm{min}$ ) under argon atmosphere. The observation of the phases was performed using an optical microscope (ZEISSICM405) and a scanning electron microscope (SEM-JEOL).

The electrochemical tests were conducted using a VoltaLAB PGZ301 potentiostat. The corrosive medium consisted of neutral aqueous solution containing $10^{-3} \mathrm{M} \mathrm{NaHCO}_{3}$ and $10^{-3} \mathrm{M} \mathrm{Na}_{2} \mathrm{SO}_{4}$. The polarisation curves are plotted in potentiodynamic mode. Potential was scanned from $-0.8 \mathrm{~V} /$ SCE to $+1 \mathrm{~V} / \mathrm{SCE}$ in the direction of the increasing potentials at a scanning rate of $1 \mathrm{mV} / \mathrm{s}$. Before each polarisation, the 


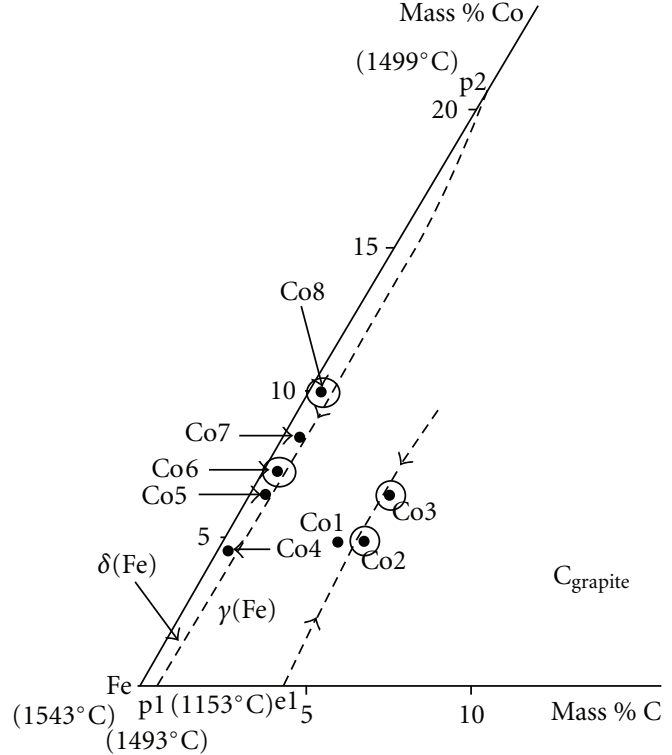

FIGURE 1: Liquidus surface projection of the $\mathrm{Fe}-\mathrm{Co}-\mathrm{C}$ system in the iron-rich corner (metastable system) [1] showing the studied alloys (encircled).

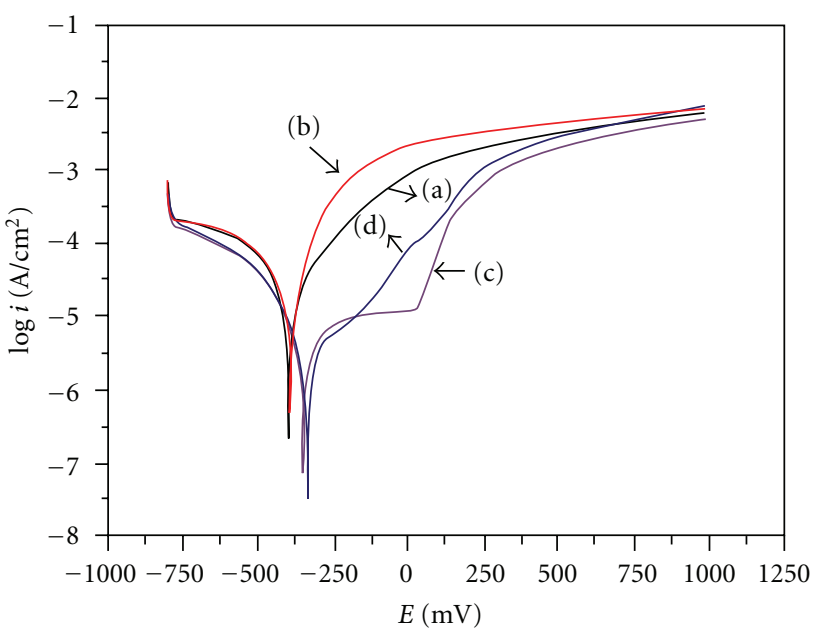
(a) - $\mathrm{Co} 2$
(c) $-\operatorname{Co6}$
(b) $-\mathrm{Co} 3$
(d) $-\operatorname{Co} 8$

Figure 2: Potentiodynamic polarisation curves of $\mathrm{Co} 2, \mathrm{Co} 3$, Co6, and $\mathrm{Co} 8$ alloys in nondeaerated solution $\mathrm{NaHCO}_{3} 10^{-3} \mathrm{M}+$ $\mathrm{Na}_{2} \mathrm{SO}_{4} 10^{-3} \mathrm{M}$, at $25^{\circ} \mathrm{C}$.

working electrodes were immersed in the test solution for $45 \mathrm{~min}$. The electrochemical experiments were carried out at $25^{\circ} \mathrm{C}$ with agitation in presence of oxygen.

\section{Results and Discussion}

In an earlier study [1], the compilation of the differential thermal analysis results in relation to the observed microstructures as well as the analysis of different phases allows us to establish the solidification paths of the studied alloys. Thus, the primary crystallization phases and the univariant

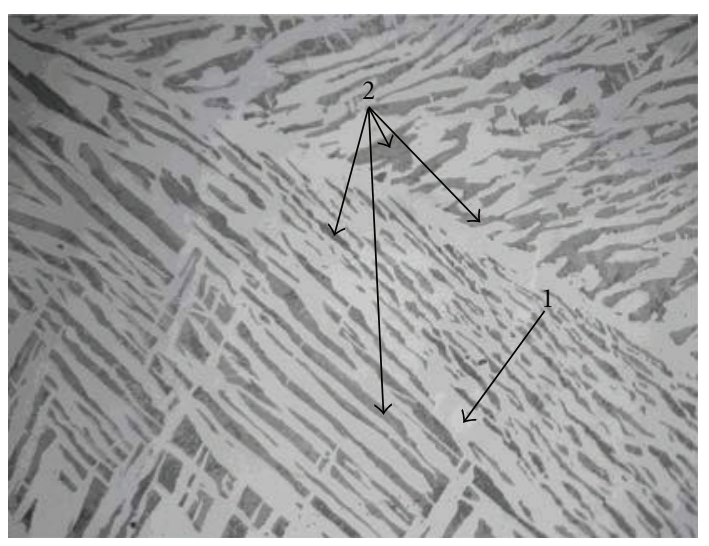

Figure 3: Optical micrograph $(\times 200)$ showing the matrix $(1)$ and pearlite (2).

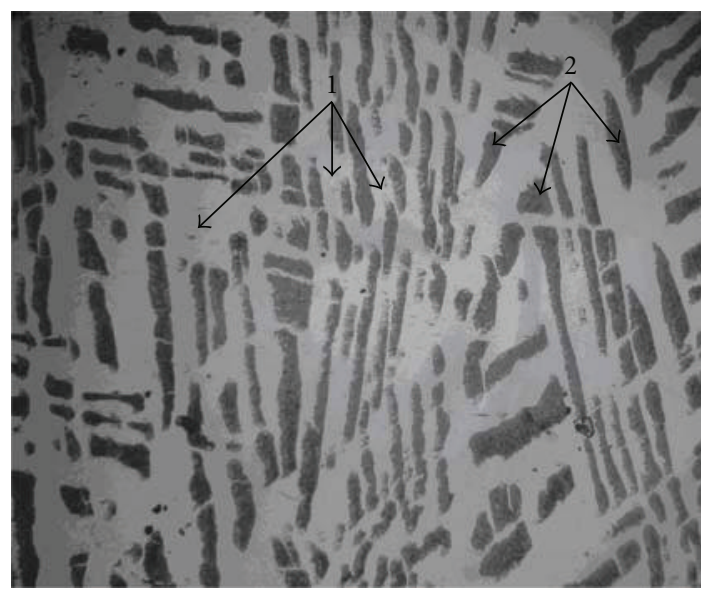

Figure 4: Co8 optical micrograph $(\times 200)$ showing the matrix $(1)$ and pearlite (2).

reactions have been identified. The obtained results are summarized in Table 1. The proposed liquidus surface projection of Fe-Co-C system in the iron-rich corner, presented in Figure 1, shows, for the studied alloys, the presence of two primary crystallization phases $(\delta(\mathrm{Fe})$ and graphite) as well as two univariante lines: eutectic $\mathrm{L} \leftrightarrow \gamma(\mathrm{Fe})+\mathrm{C}_{\text {graphite }}$ and peritectic $\mathrm{L}+\delta(\mathrm{Fe}) \leftrightarrow \gamma(\mathrm{Fe})$. The studied alloys considered in this work are also shown in Figure 1 (encircled).

Potentiodynamic polarisation curves of the studied alloys in nondeaerated solution containing $10^{-3} \mathrm{M} \mathrm{NaHCO}_{3}$ and $10^{-3} \mathrm{M} \mathrm{Na}_{2} \mathrm{SO}_{4}$ at $25^{\circ} \mathrm{C}$ are presented in Figure 2. The corresponding electrochemical parameters are given in Table 2.

We gathered in Table 3 corrosion current densities $\left(i_{\text {cor }}\right)$ of the ternary FeCoC alloys with, respectively, the $\mathrm{Fe} / \mathrm{C}$ ratio for each alloy. The results obtained for these alloys show that the corrosion current densities increase with the diminution of the $\mathrm{Fe} / \mathrm{C}$ ratio.

Co6 and Co8 steels have a better corrosion resistance than $\mathrm{Co} 3$ and $\mathrm{Co} 2$ cast iron. This would be allotted to more important carbon content in cast iron.

The Co8 alloy corrosion current density is slightly lower than that of Co6. For these two alloys, the effect of carbon 
TABle 1: Compositions, transformation temperatures, and solidification sequences of FeCoC studied alloys. (*Temperature not detected by our differential thermal analysis apparatus limited to temperature lower than $1550^{\circ} \mathrm{C}$ ).

\begin{tabular}{|c|c|c|c|c|c|}
\hline \multirow{2}{*}{ Alloy } & \multicolumn{3}{|c|}{ Compositions (wt. \%) } & \multirow{2}{*}{ Temperatures $/\left({ }^{\circ} \mathrm{C}\right)$} & \multirow{2}{*}{ Solidification sequences } \\
\hline & $\mathrm{Fe}$ & Co & $\mathrm{C}$ & & \\
\hline \multirow{4}{*}{$\mathrm{Co} 2$} & \multirow{4}{*}{90.96} & \multirow{4}{*}{4.84} & \multirow{4}{*}{4.20} & $*$ & $\mathrm{~L} \leftrightarrow \mathrm{C}_{\text {graphite }}$ \\
\hline & & & & 1163 & $\mathrm{~L} \leftrightarrow \gamma(\mathrm{Fe})$ \\
\hline & & & & 1150 & $\mathrm{~L} \leftrightarrow \gamma(\mathrm{Fe})+\mathrm{C}_{\text {graphite }}$ \\
\hline & & & & 753 & Pearlite \\
\hline \multirow{4}{*}{ Co3 } & \multirow{4}{*}{89.37} & \multirow{4}{*}{6.50} & \multirow{4}{*}{4.13} & * & $\mathrm{L} \leftrightarrow \mathrm{C}_{\text {graphite }}$ \\
\hline & & & & 1170 & $\mathrm{~L} \leftrightarrow \gamma(\mathrm{Fe})$ \\
\hline & & & & 1153 & $\mathrm{~L} \leftrightarrow \gamma(\mathrm{Fe})+\mathrm{C}_{\text {graphite }}$ \\
\hline & & & & 763 & Pearlite \\
\hline \multirow{4}{*}{ Co6 } & \multirow{4}{*}{90.90} & \multirow{4}{*}{8.45} & \multirow{4}{*}{0.65} & 1496 & $\mathrm{~L} \leftrightarrow \delta(\mathrm{Fe})$ \\
\hline & & & & 1416 & $\mathrm{~L}+\delta(\mathrm{Fe}) \leftrightarrow \gamma(\mathrm{Fe})$ \\
\hline & & & & 830 & $\gamma(\mathrm{Fe}) \leftrightarrow \alpha(\mathrm{Fe})$ \\
\hline & & & & 756 & Pearlite \\
\hline \multirow{4}{*}{$\operatorname{Co} 8$} & \multirow{4}{*}{89.52} & \multirow{4}{*}{10.00} & \multirow{4}{*}{0.48} & 1477 & $\mathrm{~L} \leftrightarrow \delta(\mathrm{Fe})$ \\
\hline & & & & 1463 & $\mathrm{~L}+\delta(\mathrm{Fe}) \leftrightarrow \gamma(\mathrm{Fe})$ \\
\hline & & & & 812 & $\gamma(\mathrm{Fe}) \leftrightarrow \alpha(\mathrm{Fe})$ \\
\hline & & & & 772 & Pearlite \\
\hline
\end{tabular}

TABLE 2: Electrochemical parameters of FeCoC ternary alloys corrosion (immersed in $10^{-3} \mathrm{M} \mathrm{NaHCO}_{3}+10^{-3} \mathrm{M} \mathrm{Na}_{2} \mathrm{SO}_{4}$, at $25^{\circ} \mathrm{C}$ ).

\begin{tabular}{|c|c|c|c|c|c|}
\hline Alloy & $E_{\text {cor }} /(\mathrm{mV} / \mathrm{ECS})$ & $i_{\text {cor }} /\left(\mu \mathrm{A} / \mathrm{cm}^{2}\right)$ & $R_{p} /\left(\mathrm{k} \Omega \cdot \mathrm{cm}^{2}\right)$ & $\beta_{a} /(\mathrm{mV} / \mathrm{dec})$ & $\beta_{c} /(\mathrm{mV} / \mathrm{dec})$ \\
\hline $\mathrm{Co} 2$ & -395 & 16.8 & 1.7 & 169 & -179 \\
\hline Co3 & -390 & 18.2 & 1.3 & 99 & -178 \\
\hline Co6 & -347 & 1.8 & 9.3 & 111 & -82 \\
\hline $\operatorname{Co} 8$ & -337 & 1.7 & 9.8 & 110 & -88 \\
\hline
\end{tabular}

TABLe 3: Variation of $i_{\text {cor }}$ according to the Fe/C ratio.

\begin{tabular}{lcccc}
\hline Alloy & Co8 & Co6 & Co2 & Co3 \\
\hline$i_{\text {cor }}\left(\mu \mathrm{A} \cdot \mathrm{cm}^{-2}\right)$ & 1.7 & 1.8 & 16.8 & 18.2 \\
$\mathrm{Fe} / \mathrm{C}$ & 186.5 & 184.5 & 21.66 & 21.64 \\
\hline
\end{tabular}

and cobalt content does not appear. However, the microstructures of these alloys (Figures 3 and 4) present the same phases except that the pearlite structure is finer in Co6 alloy. This could explain the light increase of Co6 alloy corrosion current density.

In fact, it was reported that pearlitic structures corrode faster than spheroidized materials and steels containing fine pearlite corrode rapidly than those with coarse pearlite. In addition, the degree of dispersion of the carbide is quantitatively characterized by the total amount of interfacial contact between the ferrite and cementite phases [5-8].

In addition, $\mathrm{Co} 2$ alloy is more resistant than $\mathrm{Co} 3$ alloy in the experimental conditions of this study. The examination of the microstructures of these two samples (Figures 5 and 6) shows that the structure of carbon graphite is finer in $\mathrm{Co} 3$ alloy. This would lead to an increase of corrosion current density [9].

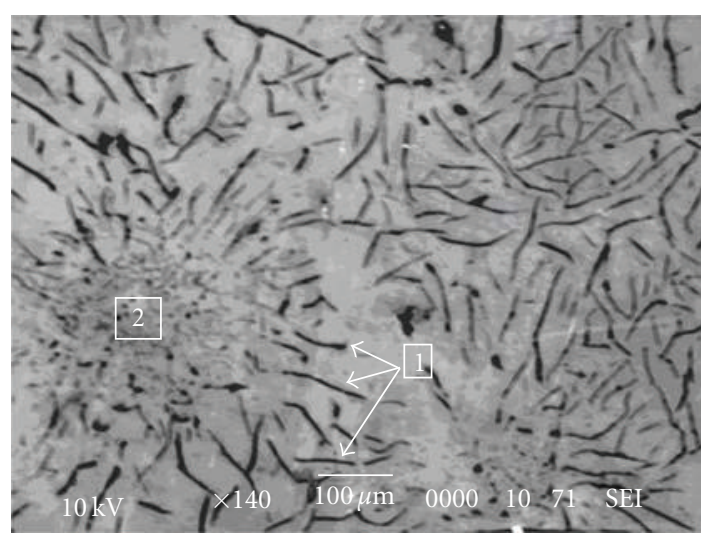

FIGURE 5: Co2 electron micrograph showing graphite (1) and $\gamma \mathrm{Fe} / \mathrm{C}$ eutectic (2).

\section{Conclusion}

This work follows the study concerning the solidification behavior of iron-based FeCoC ternary alloys. The electrochemical behavior of some of these alloys is reported to solidification observed microstructures.

The results show the presence of two primary crystallization phases $(\delta(\mathrm{Fe})$ and graphite) as well as two univariante 


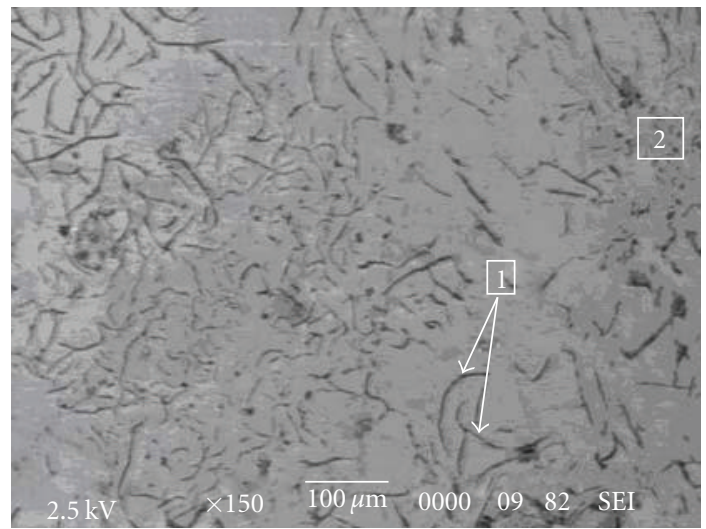

Figure 6: Co3 electron micrograph showing graphite (1) and $\gamma \mathrm{Fe} / \mathrm{C}$ eutectic (2).

lines: peritectic $\mathrm{L}+\delta(\mathrm{Fe}) \leftrightarrow \gamma(\mathrm{Fe})$ and eutectic $\mathrm{L} \leftrightarrow \gamma(\mathrm{Fe})+$ Craphite.

The interpretation of the electrochemical results in relation with the observed microstructures leads to conclude that Co6 and Co8 steels have better corrosion resistant than Co2 and $\mathrm{Co} 3$ cast iron because of the more important carbon content in cast iron. Moreover, the corrosion current density increases with the decrease of in the $\mathrm{Fe} / \mathrm{C}$ ratio. In addition, it was noted that the corrosion current density increases when the morphology is finer.

\section{References}

[1] F. Haddad, S. E. Amara, and R. Kesri, "Liquidus surface projection of the Fe-Co-C ternary system in the iron-rich corner," International Journal of Materials Research, vol. 99, no. 9, pp. 942-946, 2008.

[2] M. Hawkins, "Why we need cobalt," Transactions of the Institutions of Mining and Metallurgy B, vol. 110, may/aug, pp. B66B70, 2001.

[3] J. L. MARIÉ, Tiré à part de Travail \& Sécurité, juillet-août no 609 ED 5011-5000ex, ISSN 0373-1944, p.p. 1-4, 2001.

[4] C. Chengyun, G. Zuoxing, L. Yuhua et al., "Characteristics of cobalt-based alloy coating on tool steel prepared by powder feeding laser cladding," Optics \& Laser Technology, vol. 39, no. 8, pp. 1544-1550, 2007.

[5] H. J. Cleary and N. D. Greene, "Corrosion properties of iron and steel," Corrosion Science, vol. 7, no. 12, pp. 821-831, 1967.

[6] A. A. Abdul Azim, M. M. Anwar, and S. H. Sanad, "Potentiokinetic study of the effect of $\mathrm{C}$ on corrosion of some steels in alkaline solutions," Corrosion Science, vol. 9, no. 6, pp. 405-412, 1969.

[7] H. J. Cleary and N. D. Greene, "Electrochemical properties of Fe and steel," Corrosion Science, vol. 9, no. 1, pp. 3-13, 1969.

[8] W. J. Tomlinson and K. Giles, "The microstructures and corrosion of a $0.79 \mathrm{C}$ steel tempered in the range $100-700 \circ \mathrm{C}$," Corrosion Science, vol. 23, no. 12, pp. 1353-1359, 1983.

[9] L. L. Shreir, R. A. Jarman, and G. T. Burstein, Corrosion, vol. 1 of Metal/Environment Reactions, Butterworth Heinemann, Oxford, UK, 2000. 


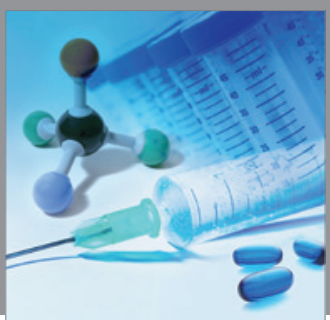

International Journal of

Medicinal Chemistry

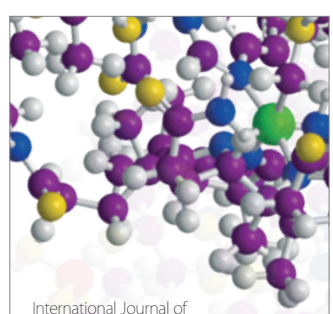

Carbohydrate Chemistry

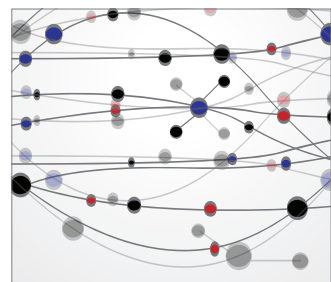

The Scientific World Journal
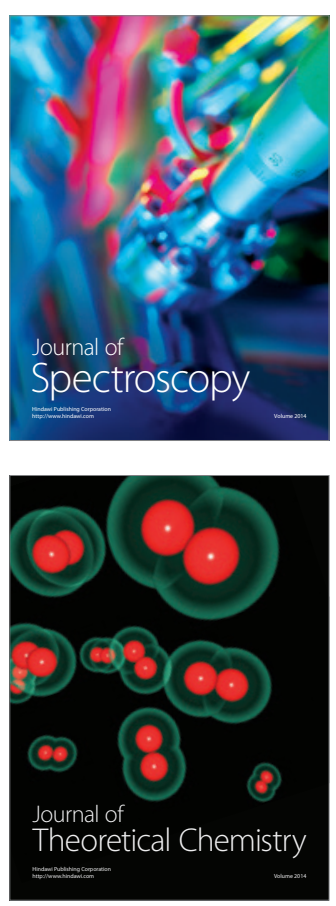
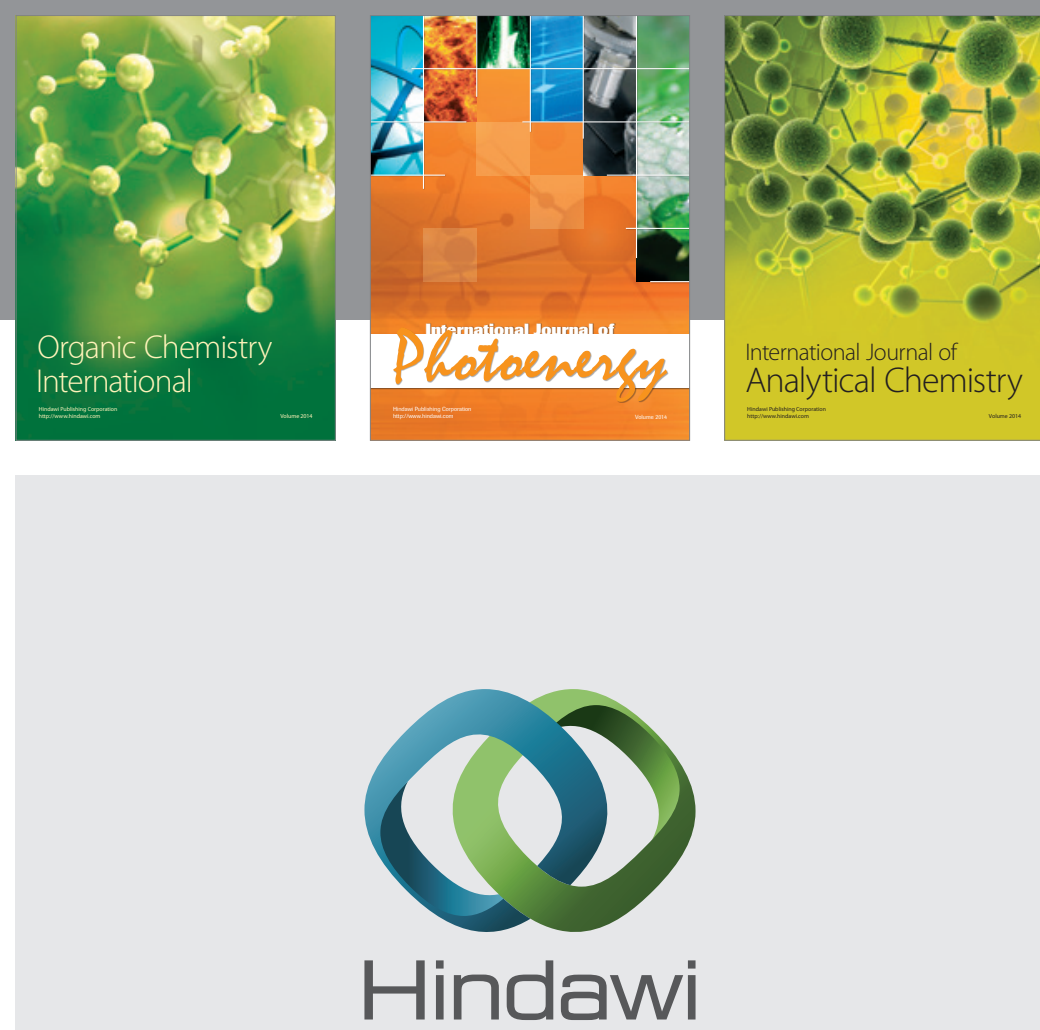

Submit your manuscripts at

http://www.hindawi.com
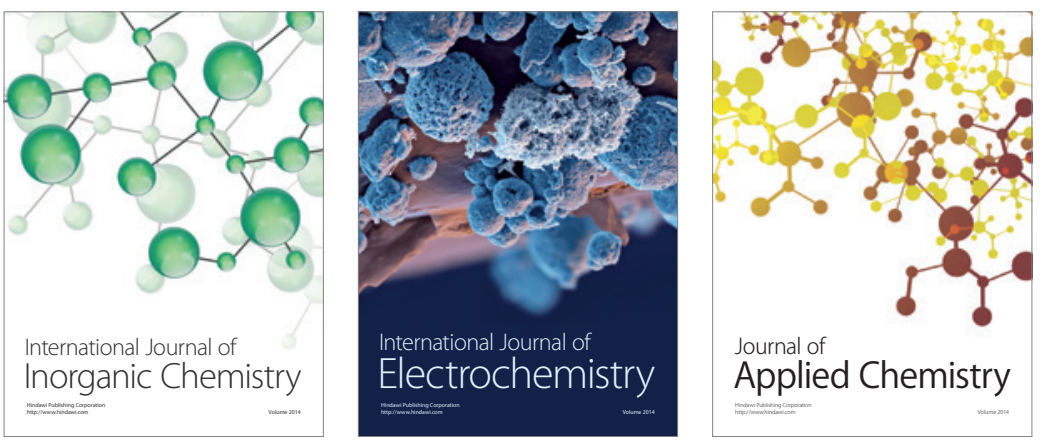

Journal of

Applied Chemistry
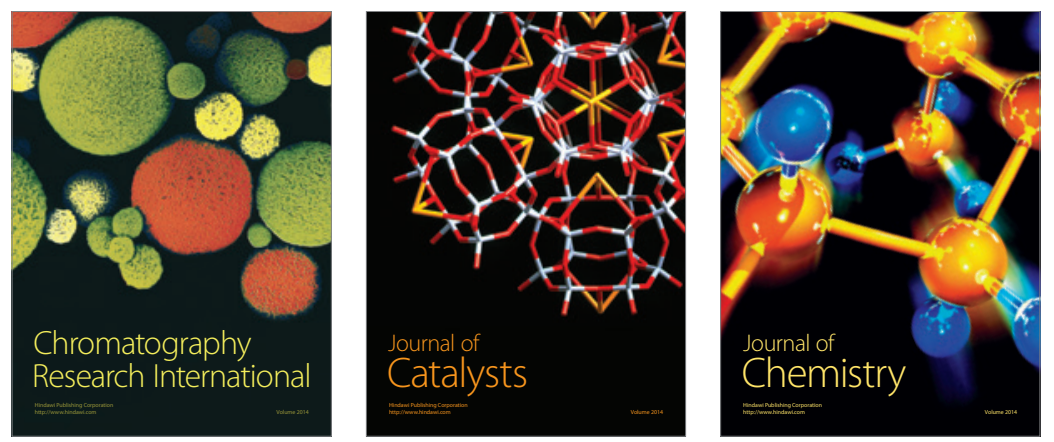
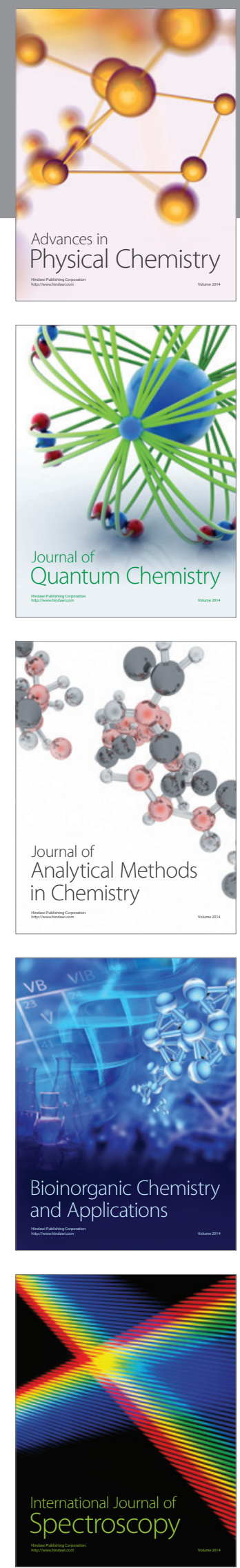